\title{
Turbulence Effect on Gas Transport in Three Contrasting Forest Soils
}

\section{Martin Maier* \\ Helmer Schack-Kirchner \\ Institute of Soil Science and Forest \\ Nutrition \\ Univ. of Freiburg \\ 79085 Freiburg im Breisgau, Germany}

\section{Marc Aubinet}

Stéphanie Goffin

Unité de Physique des Biosystèmes

Faculté Universitaire des Sciences

Agronomiques de Gembloux

5030 Gembloux, Belgium

\section{Bernard Longdoz}

Florian Parent

Unité d'Ecophysiologie forestière

INRA Centre de Nancy

F54280 Champenoux, France
Atmospheric turbulence can affect soil gas transport, and thus violates the assumption that molecular diffusion is the only relevant transport mechanism in the soil. Due to the oscillating character of turbulence-induced pressure pumping the net vertical air flow into/out of the soil is zero. Yet, the dispersion processes induced by the oscillating air movement in the soil pores enhance the gas exchange in the soil, and should be considered when the gradient method is applied. We developed a simple lab method to test the impact of turbulence-driven pressure pumping on soil gas transport using neon as a tracer gas. The experiment was conducted using soil core samples from three contrasting forest sites. The ratio of air permeability and air-filled pore-volume, $k_{\mathrm{a}} / \varepsilon$, was found to be suitable to assess the sensitivity of soil gas transport to the pressure-pumping effect. The pressure-pumping effect reached up to $60 \%$ of the diffusive flux rates depending on the intensity of pressure pumping. We conclude that the turbulence effect can substantially influence soil gas transport in field studies, especially at sites with a high $k_{\mathbf{a}} / \varepsilon$ value $>1000 \mathrm{um}^{2}$. Therefore, we recommend taking this effect into account when soil gas flux is determined using the gradient method.

Abbreviations: $\alpha$, dispersivity; $C_{\text {out }}$ neon concentration at the chamber outlet; $\varepsilon$, airfilled pore-space; $D_{0}$, diffusion coefficient in air; $D_{\text {disp }}$ dispersion term; $D_{\text {disp }} / D_{0}$, relative dispersion coefficient; $D_{\text {res }}$, resulting diffusivity; $D_{S}$, effective gas diffusion coefficient, $D_{S}$ ' $D_{0}$, relative diffusion coefficient; $k_{a^{\prime}}$ air permeability, $\kappa_{p^{\prime}}$ pressure diffusivity; $\eta$, viscosity of the air; $p$, pressure fluctuations; $P_{0}$, mean atmospheric pressure; $v$, gas velocity.

$\mathrm{T}$ he production of $\mathrm{CO}_{2}$ in the soil by roots, microorganisms, and macrofauna not only varies temporally and spatially on the plot and the landscape level, but also vertically with soil depth. Using chamber techniques it is possible to address the spatial and the temporal variation of the $\mathrm{CO}_{2}$ efflux at a site. However, it is impossible to gain information about the vertical distribution of $\mathrm{CO}_{2}$ sources within the soil profile, which is important to improve our understanding of the influence of parameters varying with depth. The gradient method (DeJong and Schappert, 1972; Davidson et al., 2006; Massman, 2006; Pumpanen et al., 2008; Schack-Kirchner et al., 2011) could potentially overcome this limitation. Although the main gas transport process in soils is diffusion, advection can be important under certain circumstances such as large changes in barometric pressure (Clements and Wilkening, 1974; Elberling et al., 1998), a rising ground water table (Jiao and Li, 2004; Maier et al., 2010), or wind-induced stationary pressure differences across topographical features (Amos et al., 2009; Bowling and Massman, 2011). This advective contribution can be integrated in the gradient method using a suitable gas transport model (e.g., Fang and Moncrieff, 1999). The

Soil Sci. Soc. Am. J.

doi:10.2136/sssaj2011.0376

Received 4 Nov. 2011

*Corresponding author (martin.maier@bodenkunde.uni-freiburg.de)

(C) Soil Science Society of America, 5585 Guilford Rd., Madison WI 53711 USA

All rights reserved. No part of this periodical may be reproduced or transmitted in any form or by

any means, electronic or mechanical, including photocopying, recording, or any information storage and retrieval system, without permission in writing from the publisher. Permission for printing and for reprinting the material contained herein has been obtained by the publisher. 
major challenge here is the measurement of the pressure gradient, which can be hardly detectable (Maier et al., 2010).

In addition to these static pressure gradients, resulting from low-frequency pressure changes (time scale of hours to days), there are also high-frequency pressure fluctuations $(>0.1 \mathrm{~Hz})$ due to atmospheric turbulence. Field studies showed that these highfrequency pressure fluctuations can strongly influence soil gas concentrations (Hirsch et al., 2004; Seok et al., 2009; Flechard et al., 2007, Maier et al., 2010), and hence also soil gas transport and efflux. It is important to note that high-frequency pressure fluctuations do not induce a persisting pressure gradient as wind with laminar flow over topographical features does. If laminar wind is flowing steadily, for example, over a rock pile, a persistent pressure difference between the upwind to the downwind side can result in a continuous air flow through the porous pile (Amos et al., 2009). But in the case of a flat but complex surface, such as a plain covered by forest, wind will only induce turbulent flow with oscillating pressure fluctuations, and the net air flow into or out of the soil is zero. Nevertheless the observed effect on soil gas concentrations occurs throughout the entire profile (Seok et al., 2009; Maier et al., 2010). The pressure pumping induces an oscillating flow in the soil pores that seems to "enhance the diffusion" of the soil gas. This effect of turbulence-driven pressure pumping can be attributed to dispersion processes (Takle et al., 2004).

Fukuda (1955) theoretically examined the movement of air in soil due to "wind gustiness". Some years later, Scotter and Raats (1968) presented results from an experiment using a piston to impose a small sinusoidal movement on the air in a cylinder packed with sand. They observed an enhancement of gas exchange through the sand cores, and thus could clearly demonstrate the importance of the dispersion effect due to oscillating air flow. Recent research about gas dispersion in the soil focused on the dependence of dispersivity on substrate type (Hamamoto et al., 2009; Gidda et al., 2006; Sharma and Poulsen, 2010). The set-up used in these experiments is designed to accurately determine the dispersion induced by continuous gas flow and not by oscillating gas flows. To model the transport of contaminants, for example, by soil vapor extraction, these measurements are close to reality. Yet, this standard method (e.g., Hamamoto et al., 2009) does not allow relating the driving force (turbulence), the oscillating flow due to pressure pumping, and the effect of "enhanced diffusion".

Modeling $\mathrm{CO}_{2}$ flux in a snowpack, Massman and Frank (2006) integrated diffusion, viscous flow, and also dispersion into the gradient method. Based on modeling with synthetic pressurepumping data, Poulsen and Møldrup (2006) also emphasized the importance of pressure pumping and addressed the crucial role of soil physical parameters on soil-atmosphere gas exchange. There are several transfer functions available that can be used to derive the parameters that are difficult to measure, for example, the diffusion coefficient $D_{S}$, from parameters that can be easily determined, for example, the air-filled pore-volume (Millington, 1959; Moldrup et al., 1999). Yet, these functions are not able to fully reflect sitespecific factors, which can be crucial if the relevance of pressure pumping must be evaluated for different sites.
In this paper (i) we discuss the transport mechanisms underlying the turbulence-driven pressure pumping and present a conceptual model. We propose to integrate the pressurepumping induced dispersion and the diffusion as "apparent diffusion", which easily could be used in field studies applying the gradient method. (ii) We examine the effect of pressure pumping on gas transport through undisturbed soil samples from three sites using a new experimental design. The experimental data are analyzed to evaluate the impact of relevant soil physical parameters on the sensitivity of soil gas transport to pressure pumping. The laboratory results help us to assess the sensitivity of the soil to the pressure-pumping effect at the three forest sites where the gradient method is currently applied.

\section{TURBULENCE-DRIVEN PRESSURE PUMPING}

The amplitudes of high-frequency pressure fluctuations are very small compared to the barometric pressure. Hence, the vertical air flow into/out of the soil is very small compared to the depth of a soil (a pressure fluctuation of $10 \mathrm{~Pa}$ can compress the soil air column by $0.1 \mathrm{~mm}$, if a barometric pressure of $100 \mathrm{kPa}$ and a soil depth of $1 \mathrm{~m}$ is assumed). Though, the movement of the soil air column can be substantial compared to the diameter of the soil pores. As a result of the alternating direction of the pressure fluctuation, the net vertical air flow into/out of the soil is zero, although air flow occurs within the soil pores.

The effect of turbulence-driven pressure pumping on soil gas transport can be basically explained by dispersion induced by the oscillating airflow in the soil pores. The phenomenon of dispersion is well-known, for example, from contaminant transport in ground water (Delgado, 2006), but is also relevant in the gas phase of porous media (Scotter and Raats, 1969; Costanza-Robinson and Brusseau, 2002).

Generally, the dispersion in soil pores can be attributed to molecular diffusion and mechanical mixing components. Figure 1 visualizes the gas transport in a soil pore driven only by diffusion (left), and additionally driven by pressure pumping (middle: downward movement of the soil air column; right: upward movement). The enhancement of the gas transport due to pressure pumping can be mainly explained by three effects.

First, dead-end pores do not contribute to the gas transport under calm conditions, and there is no concentration gradient between dead-end pore and main pore (Fig. 1 left: A). But when the air column is oscillating, the vertical concentration gradient in the main pore results in an additional, lateral concentration gradient between the dead-end pore and the main pore with oscillating direction (Fig. 1 middle, right: A). When the air column in the main pore is below the neutral point, the lateral concentration gradient leads to diffusion of $\mathrm{CO}_{2}$ molecules into the main pore (Fig. 1 middle: A). When the air column is above the neutral point (that means air from a deeper position and a higher $\mathrm{CO}_{2}$ concentration is shifted upward in the main pore), the $\mathrm{CO}_{2}$ molecules diffuse from main pore into the dead-end pore, "loading" the dead-end pore with $\mathrm{CO}_{2}$ (Fig. 1 right: A). Thus, the oscillating air acts as a "ladder". 


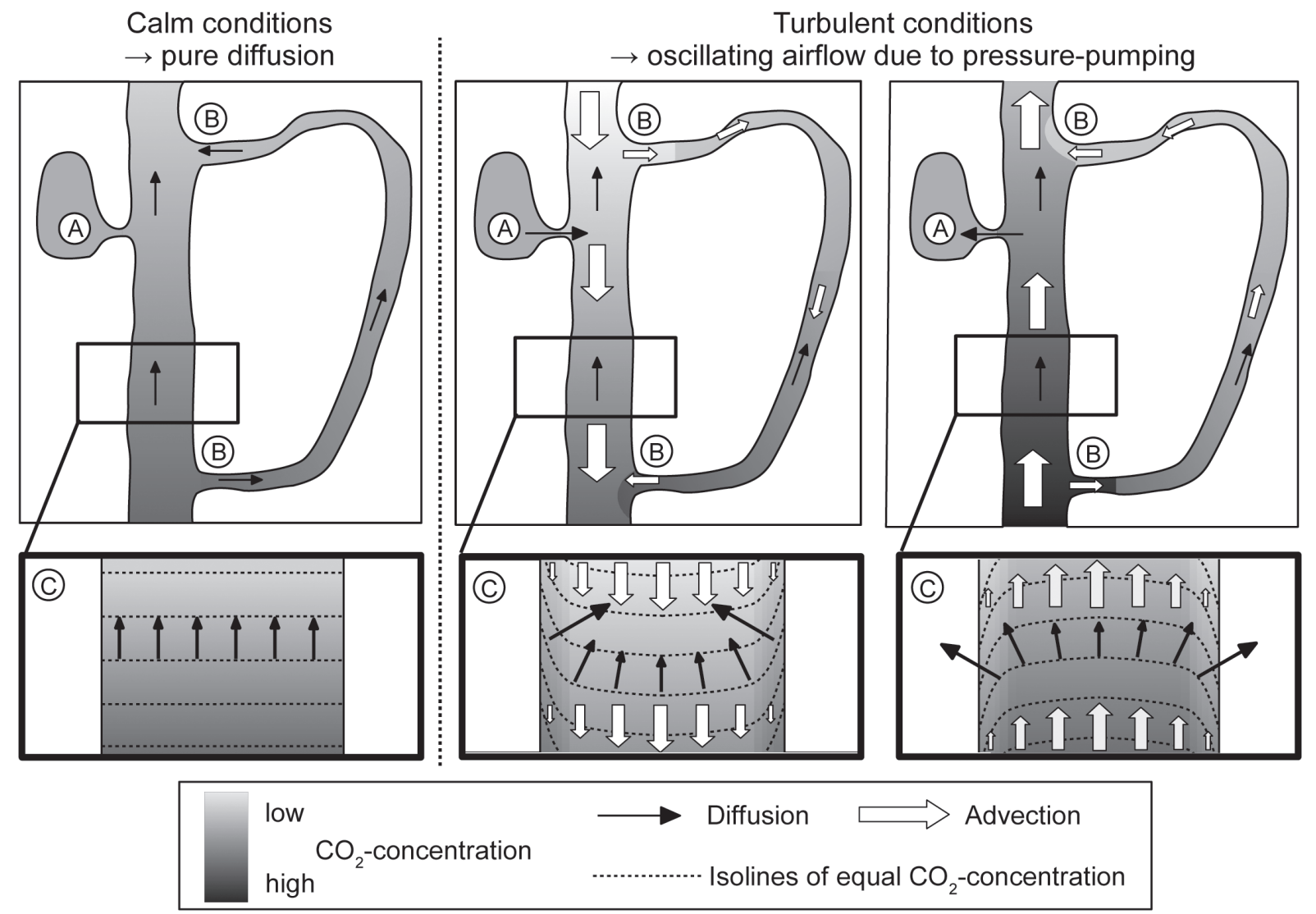

Fig. 1. Soil gas transport under calm and under turbulent conditions including diffusion, advection, and dispersion.

Second, there is mechanical mixing of soil air at the intersection of pores (Fig. 1 middle, right: B). Because of different permeability, the flow rate of air differs between the soil pores leading to horizontal concentration heterogeneity, and finally to an irreversible mixing of air with different $\mathrm{CO}_{2}$ concentrations.

Third, even within a single pore the gas velocity differs depending on the distance to the pore wall due to wall friction. As a consequence the concentration isolines, which are straight under calm atmospheric conditions, become curved under turbulent conditions due to pressure pumping (Fig. 1:C). When the oscillating air column is below the neutral point, the $\mathrm{CO}_{2}$ molecules close to the wall diffuse toward the center of the pore (Fig. 1 middle: C) and are then transported upward. As soon as the air column is above the neutral point, the direction of the diffusion is reversed toward the pore wall by diffusion (Fig. 1 right: $\mathrm{C}$ ). Therefore the $\mathrm{CO}_{2}$ molecules preferentially use the upward movement of the oscillating air column.

Theoretically, in a vertically homogeneous soil, gas transport can be calculated using the advection-diffusion-dispersion equation:

$$
\frac{\partial C}{\partial t}=\left(D_{S}+\alpha|v|\right) \frac{\partial^{2}}{\partial z^{2}}-v \frac{\partial C}{\partial z}+S,
$$

where $C$ is the concentration of the gas species $\left(\mu \mathrm{mol} \mathrm{mol}^{-1}\right), t$ is time (s), $D_{S}$ is the gas diffusion coefficient in the soil $\left(\mathrm{m}^{2} \mathrm{~s}^{-1}\right)$, $\alpha$ is the dispersivity $(\mathrm{m}), z$ is the depth $(\mathrm{m}), S$ is the source term $\left(\mu \mathrm{mol} \mathrm{mol}^{-1} \mathrm{~s}^{-1}\right)$, and $v\left(\mathrm{~m} \mathrm{~s}^{-1}\right)$ is the vertical velocity of the airflow. The dispersion coefficient $D_{\text {disp }}\left(\mathrm{m}^{2} \mathrm{~s}^{-1}\right)$ is the product of $\alpha$ and $v, D_{\text {disp }}=\alpha|v|$, where $v$ is an absolute value because dispersion happens in both directions and is always positive. If we apply Eq. [1] to the turbulence-driven pressure pumping on a time scale larger than $5 \mathrm{~min}$, the mean of $v$ becomes zero, because of the oscillating character of the flow. Hence, the advective contribution to the gas transport is zero. However, the instantaneous gas velocity and thus the mean absolute value of $v$ is not zero and we have to consider dispersion. It is $D_{\text {disp }}$ that represents the pressure-pumping effect, which we want to integrate in the modeling of field studies. We define the sum of the diffusion and dispersion coefficients as the resulting exchange coefficient $D_{\text {res }}\left(\mathrm{m}^{2} \mathrm{~s}^{-1}\right): D_{\text {res }}=D_{S}+D_{\text {disp. }}$. Hence, the pressure-pumping induced dispersion effect can be dealt with as an additive term in the regular diffusion equation using $D_{\text {res }}$ instead of $D_{S}$.

The dispersivity $\alpha$ mainly depends on the geometry of the airfilled pores (Costanza-Robinson and Brusseau, 2002; Sharma and Poulsen, 2010), while the mean $|v|$ depends on the characteristics of the pressure fluctuation at the surface and the physical properties of the soil (Poulsen and Møldrup, 2006). The $|v|$ value at a depth is linked to the penetration of pressure fluctuations $p(\mathrm{~Pa})$ into the soil that can be obtained using (Fukuda, 1955):

$$
\frac{\partial p}{\partial t}=\kappa_{p} \frac{\partial^{2} p}{\partial z^{2}}
$$

Equation [2] is a diffusion-like equation, in which the pressure diffusivity $\kappa_{\mathrm{p}}\left(\mathrm{m}^{2} \mathrm{~s}^{-1}\right)$ is described by: 


$$
\kappa_{p}=\frac{k_{a}}{\varepsilon} \frac{P_{0}}{\eta},
$$

where $k_{\mathrm{a}}$ is air permeability $\left(\mu \mathrm{m}^{2}\right), \varepsilon$ is air-filled pore-volume $\left(\mathrm{m}^{3} \mathrm{~m}^{-3}\right), P_{0}$ the mean atmospheric pressure $(\mathrm{Pa})$, and $\eta$ is the viscosity of the air $\left(\mu \mathrm{Pa} \mathrm{s}^{-1}\right)$. While $P_{0}$ and $\eta$ represent the influence of the fluid, $k_{\mathrm{a}}$ and $\varepsilon$ reflect the dependence on physical soil properties. A higher $k_{\mathrm{a}} / \varepsilon$ ratio $\left(\mu \mathrm{m}^{2}\right)$ results in higher pressure diffusivity, and thus an easier and deeper penetration of pressure fluctuations into the soil.

Based on Eq. [1-3] and Darcy's law, Massman (2006) calculated the resulting three-dimensional pressure field and gas velocity $v$ for a layered medium. The resulting equations were used to derive reference values of $D_{\text {disp }}$ for our laboratory experiment results. However, this physically-based model needs many input parameters that are difficult to obtain in the field.

\section{MATERIALS AND METHODS Description of the Sites}

Three different forest sites (Hartheim, Germany; Hesse, France; Vielsalm, Belgium) were chosen to take undisturbed soil core samples at different depths. A meteorological tower is present at each experimental site to measure the main meteorological variables including wind speed and friction velocity. The three sites differ largely in their stand characteristics and soil properties (Table 1). The Scots pine stand at the Hartheim site has a sparse canopy and a dense understory, while the beech stand at Hesse and the mixed stand at Vielsalm have a dense canopy and no understory. The soil at Hartheim has a high porosity and is well aerated, while porosity and aeration at Vielsalm are reduced due to soil compaction. At Hesse the aeration of the topsoil is intermediate, but the subsoil shows stagnic properties.
Standard Measurements of Soil Physical Parameters

For the standard measurements of soil physical parameters (porosity, water retention characteristics, diffusivity, and air permeability) we took 127 undisturbed $200 \mathrm{~cm}^{3}$ core samples $(5 \mathrm{~cm}$ height) at different depths at the different sites. The porosity of the soil samples was determined by vacuum pycnometry and the thermogravimetric method (Hartge and Horn, 1999). To obtain the water retention curves the samples were saturated with water and then successively drained applying defined levels of water potential using a filter bed and a pressure plate.

Gas diffusivity $\left(D_{S}\right)$ was measured at different levels of water potential employing a nonstationary one-chamber method (Kühne et al., 2011), using neon as a tracer gas. The intact soil cores were placed on top of a chamber, so that gas exchange was restricted to diffusion through the soil sample. A defined amount of neon was injected into the chamber. From the decreasing neon concentration over time the diffusivity $D_{S}$ and the dimensionless relative diffusivity $D_{S} / D_{0}$ were determined.

Air permeability was measured with a device similar to that described by Iversen et al. (2001), where air flows through a soil ring sample at a constant rate. The pressure gradient across the soil sample at a given flow rate is inversely proportional to the air permeability. The device was equipped with a highly sensitive pressure sensor (GMSD 2.5 MR, 125 Greisinger Electronic GmbH; Regenstauf; Germany; sensitivity $0.1 \mathrm{~Pa}$ ). For each site the horizon-specific dependence of diffusivity and air permeability on air-filled pore volume was derived using nonlinear regression functions.

\section{Turbulence Experiment}

We developed a steady-state method to measure the resulting soil gas diffusivity, which could also be used to test the effect of turbulence-

Table 1. Description of the experimental forest sites Hartheim (Germany), Hesse (France), and Vielsalm (Belgium). Soils were classified according USDA (Soil Survey Staff, 2006) and WRB classification (FAO, 2006).

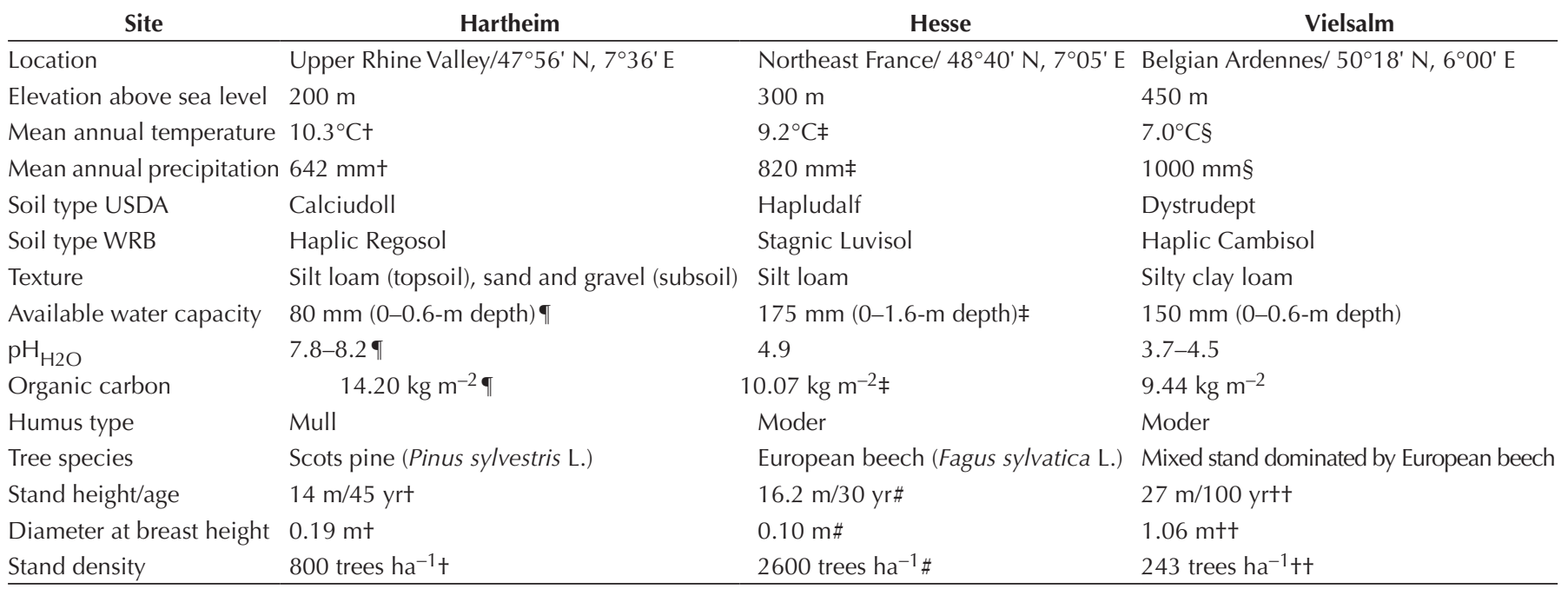

† Holst et al. (2008).

‡ Granier et al. (2008).

$\S$ Aubinet et al. (2005).

I Maier et al. (2010).

\# Granier et al. (2000).

†† Aubinet et al. (2001). 
driven pressure pumping on gas transport. The set-up was similar to that of Jassal et al. (2005). The method was modified using a peristaltic pump and neon as a tracer gas. A soil core sample $\left(200 \mathrm{~cm}^{3}\right)$ was fixed on top of an open-top chamber $\left(200 \mathrm{~cm}^{3}\right)$, through which air with a defined concentration of tracer gas was circulated. This air entered at the bottom of the chamber with a constant neon concentration of $0.1 \%$ (Fig. 2, side view). A perforated tube positioned right below the soil sample collected the air leading it to a micro-gas chromatograph (CP2002P, Chrompack, Middelburg, the Netherlands, CP-Molsieve$5 \mathrm{~A}$ column, helium as carrier gas). The flow rate into and out of the chamber was exactly the same and was controlled by a peristaltic pump. The loss of neon was restricted to diffusion through the soil sample (when turbulence above the sample is zero). After a certain time, an equilibrium situation is established and a stationary neon concentration in the chamber will be reached. No fan was located inside the chamber to avoid undesired turbulence. In this stationary situation, the tracer gas flux through the soil sample $\left(F, \mathrm{~m}^{3} \mathrm{~s}^{-1}\right)$ corresponds only to diffusion and dispersion because the source and the advective terms are zero, leading to the following equation:

$$
F=\left(D_{S}+D_{\text {disp }}\right) \frac{\partial C}{\partial z}=D_{\text {res }} \frac{\partial C}{\partial z},
$$

Thus, $D_{\text {res }}\left(\mathrm{m}^{2} \mathrm{~s}^{-1}\right)$ could be calculated by

$$
D_{S}+D_{\text {disp }}=D_{\text {res }}=\frac{F}{\Delta C / \Delta z}=\frac{\Phi\left(C_{\text {in }}-C_{\text {out }}\right)}{\left(C_{\text {out }}-C_{\text {atm }}\right) / h},
$$

where $\Phi$ is the flow rate of the pump $\left(\mathrm{m}^{3} \mathrm{~s}^{-1}\right), C_{\mathrm{in}}, C_{\text {out }}$, and $C_{\mathrm{atm}}$ the neon concentration $\left(\mu \mathrm{mol} \mathrm{mol}{ }^{-1}\right)$ at the chamber inlet, outlet and in the atmosphere, and $h$ the height of the soil sample (m).

The set-up allowed us to measure five samples simultaneously (Fig. 2, top view). To simulate a flat soil surface, the soil rings were mounted into a panel, so that the panel surface and the top of the soil samples formed a plane surface (Fig. 2, side view). This was necessary to avoid local effects and to ensure that all five samples received the same turbulence-induced pressure fluctuations. Turbulence was generated by a constantly blowing fan and a slowly turning chopper wheel. The resulting air movement across the experimental surface varied continuously, inducing pressure fluctuation at the samples surfaces. To assess the pressure pumping two of the chambers were equipped with a sensor (GMSD 2.5 MR, Greisinger Electronic $\mathrm{GmbH}$; Regenstauf, Germany) to measure the pressure fluctuations. The atmospheric turbulence was measured at $10 \mathrm{~Hz}$ using a sonic anemometer (81000V, R. M. Young Company, Traverse City, MI) installed in front of the experimental set-up.

At first, the diffusivity of the soil samples was measured under calm conditions where pressure pumping had no effect $\left(D_{\text {res }}=D_{S}\right)$. Then the turbulence generator was switched on (= turbulence Level 1) and a new steady state was reached. Then a higher turbulence level (= turbulence Level 2 ) was set. The difference between $D_{\text {res }}$ measured under calm conditions $\left(=D_{S}\right)$ and $D_{\text {res }}$ measured under turbulent conditions could be attributed to turbulence-induced dispersion $\left(D_{\text {disp }}\right)$. Analogous to $D_{S} / D_{0}$, we define the dimensionless relative dispersion coefficient $D_{\text {disp }} /$ $D_{0}$ and the relative resulting exchange coefficient $D_{\text {res }} / D_{0}$.

For this experiment we used five topsoil samples $(0-5-\mathrm{cm}$ depth) of each site at two different soil moisture levels. The friction velocity $u^{*}\left(\mathrm{~m} \mathrm{~s}^{-1}\right)$ was used as a proxy specifying the turbulence intensity (Stull, 1988). The friction velocity is obtained from $u^{*}=\sqrt{\overline{-\left(u^{\prime} w^{\prime}\right)}}$ where $u^{\prime}$ and $w^{\prime}$ are the fluctuations of the horizontal and vertical wind velocities compared to the mean values $\left(\mathrm{m} \mathrm{s}^{-1}\right)$, respectively, and $\overline{\left(u^{\prime} w^{\prime}\right)}$ represents the temporal mean value of the product of $u$ ' and $w$.

All statistical analyses were accomplished using the software SAS 9.2 (SAS Institute Inc., Cary, NC). We used the procedure PROC NLIN for nonlinear curve-fitting. To smooth the water retention curve the procedure PROC TPSPLINE was used. The effect of turbulence-driven pressure pumping on $D_{\text {res/ }} D_{0}$ was tested at $p=0.05$ using the Friedman test.

\section{RESULTS}

\section{Pore-Size Distribution, Diffusivity, and Air Permeability}

The pore-size distribution was derived from the measured soilwater retention curves, assuming radial pore geometry. At Hartheim the soil is well aerated throughout the profile, and has a large volume of macropores representing interaggregate pores (Fig. 3a). At Hesse the profile was slightly compacted in the top soil (depth $<25 \mathrm{~cm}$ ).

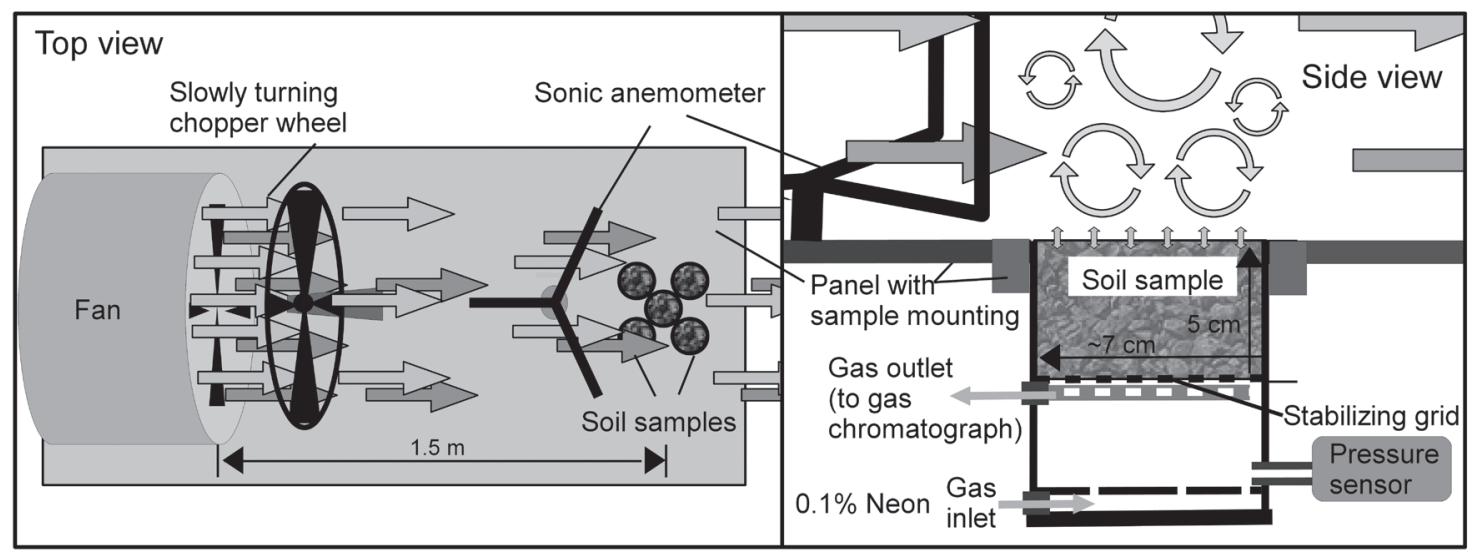

Fig. 2. Set-up of a steady-state method to measure the soil gas diffusivity under calm and the resulting soil gas diffusivity under turbulent conditions. The flow rate of the gas into and out of the chamber was controlled by a peristaltic pump. 

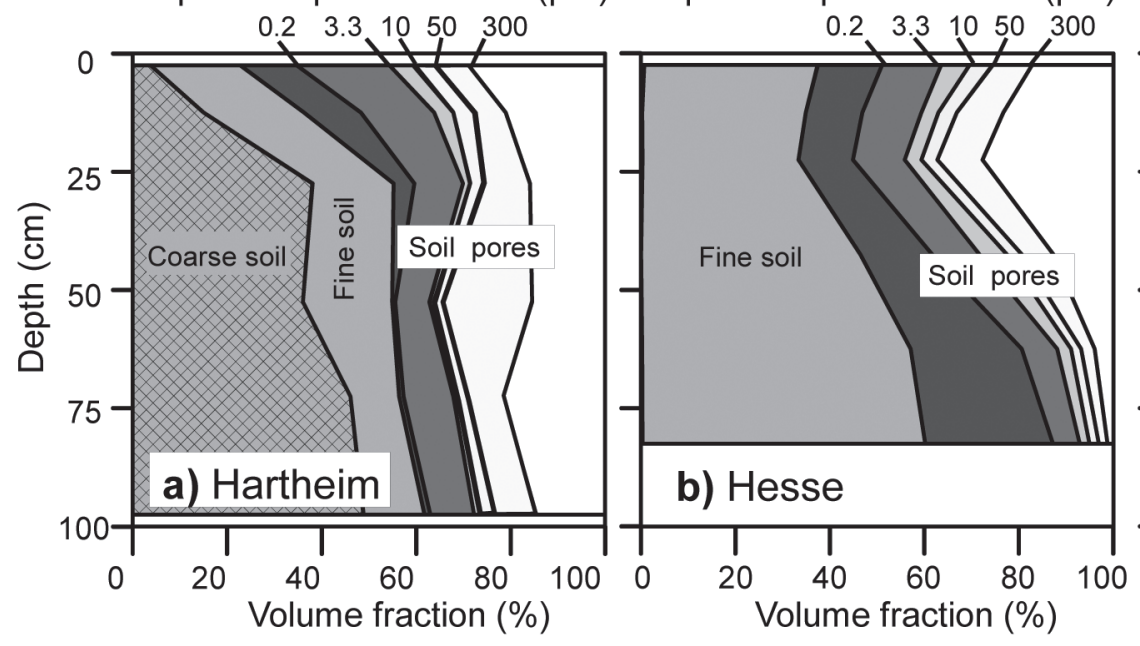

Equivalent pore diameter $(\mu \mathrm{m})$

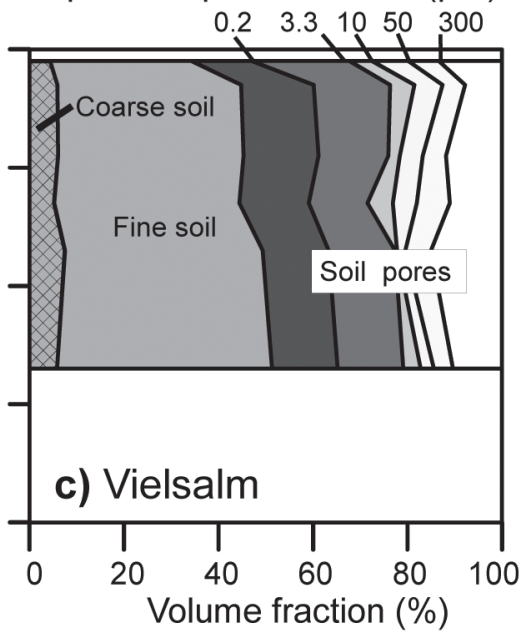

Fig. 3. Profiles of the pore-size distribution at the experimental sites. Equivalent pore diameter was derived from matric potential.

The volume of the macropores (diameter $>300 \mu \mathrm{m}$ ) diminishes at depth $>60 \mathrm{~cm}$, so aeration of the subsoil is limited (Fig. 3b). At Vielsalm traces of compaction due to the use of forestry machinery were visible in the field. Here, also the volume of the macropores (>300 $\mu \mathrm{m}$ diam.) in the top soil was lowest (Fig. 3c).

The topsoil $(0-5 \mathrm{~cm})$ at all sites revealed distinct relationships between $\varepsilon$ and $D_{S} / D_{0}$ (Fig. $4 \mathrm{a}, 4 \mathrm{~b}$, and $4 \mathrm{c}$ ). At similar $\varepsilon$ values the Vielsalm samples generally had the lowest $D_{S}$
$D_{0}$ values. The relationship between $k_{a}$ and $\varepsilon$ was more scattered (Fig. 4d, 4e, 4f), especially for the Hartheim samples where the highest $k_{a}$ values were observed. As the pore-volume decreases with soil depth, the measured $D_{S} / D_{0}$ and $k_{a}$ values decreased with depth (data not included).
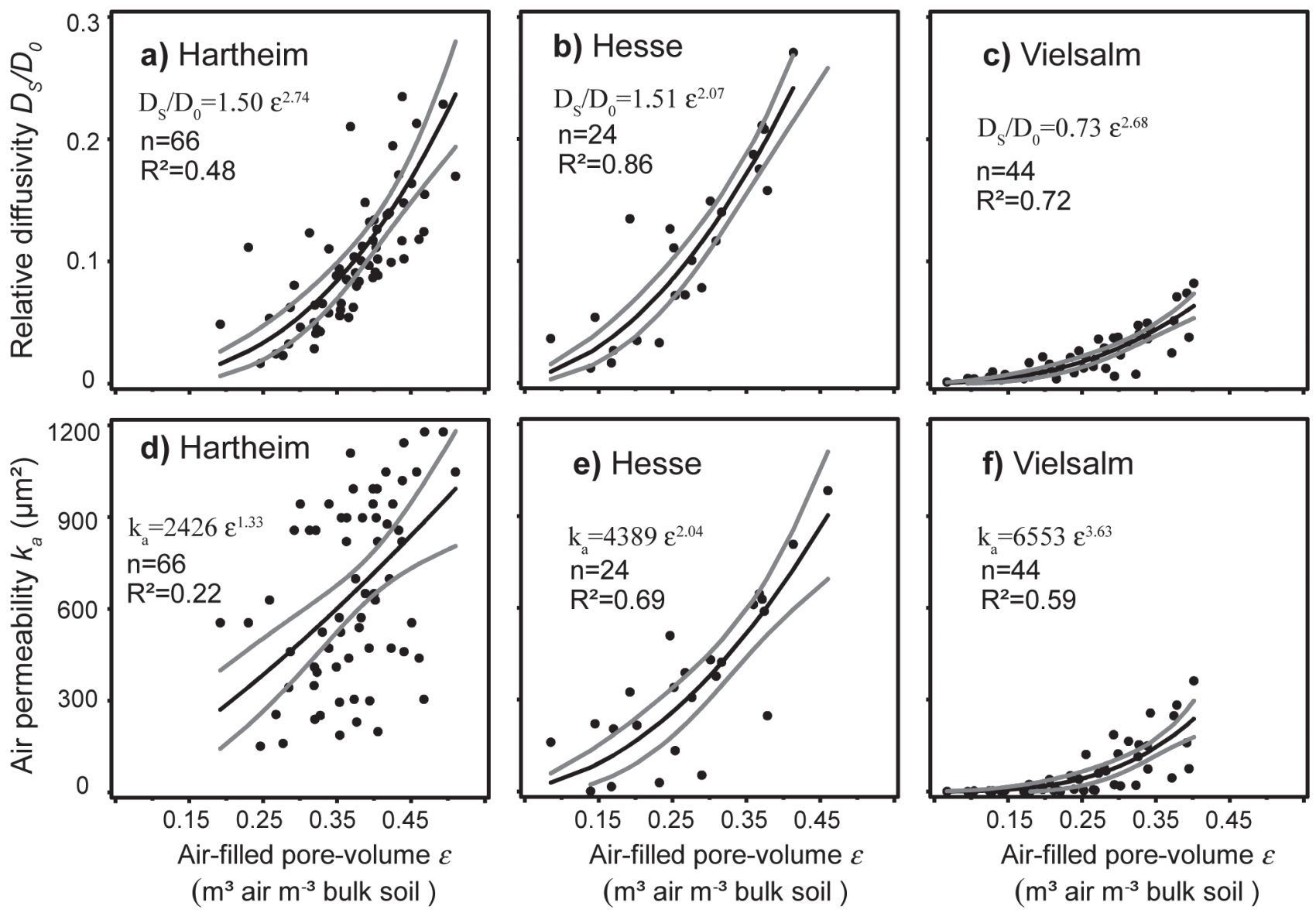

Fig. 4. (top) Relationship between the relative diffusion coefficient $D_{S} / D_{0}$ and the air-filled pore-volume $\varepsilon$ and (bottom) relationship of air permeability $k_{\mathrm{a}}$ and $\varepsilon$ of topsoil samples (0-5-cm depth). 


\section{Turbulence Experiment}

The results of a demonstration test are plotted in Fig. 5. For this run, five plastified soil samples with similar air-filled pore-volume, but distinct effective gas diffusion coefficient and air permeability were used (Fig. 5a, see legend). The soil physical properties of the samples were non-natural due to the plastification. Yet, the underlying physical principle of the pressure-pumping effect could clearly be observed on these samples. When a steady-state concentration was reached the turbulencegenerator wasswitched on (Fig. 5b) to start turbulencedriven pressure pumping. As a result the neon concentration in the chamber $\left(C_{\text {out }}\right)$ dropped substantially in some of the chambers and tended to a new steady-state concentration. $D_{S}$ was calculated from the steady-state concentration under calm conditions, where a high concentration corresponds to a low value for $D_{S}$ (see Eq. [5]). The decrease in the steady-state $C_{\text {out }}$ concentration under turbulent conditions due to the pressurepumping effect did not depend on the initial $D_{S}$ value, but rather on $k_{a}$ (see Fig. 5a). Only samples with high air permeability showed a substantial decrease in the steady-state concentration under turbulent conditions (Fig. 5a: samples 1, 2, and 5).

Unfortunately the peristaltic pump used in the experiment induced a small oscillating pressure fluctuation in the chamber. The pressure fluctuations induced by the pump were tested by sealing the chambers with solid plastic samples and were the same for all chambers. The resulting pressure fluctuations were less but still detectable when soil samples were fixed on the chambers (Fig. $5 c, 5 \mathrm{~d}$, turbulence Level 0). Samples with a higher $k_{\mathrm{a}} / \varepsilon$-value revealed lower basic pressure fluctuations, because the pressure fluctuations induced by the peristaltic pump could easily "be transported" through the sample to the atmosphere. This caused probably an overestimation of $D_{S}$. Nevertheless, the conclusions drawn for turbulence-induced $D_{\text {disp }}$ remain unchanged, because this effect was the same at all turbulence levels.

The mean value of the friction velocity $u^{*}$ was $<0.01 \mathrm{~m} \mathrm{~s}^{-1}$ under calm conditions, $0.17 \mathrm{~m} \mathrm{~s}^{-1}$ at turbulence Level 1 , and $0.34 \mathrm{~m} \mathrm{~s}^{-1}$ at turbulence Level 2. The turbulence-driven pressure fluctuations at the surface of the different soil samples were the same at a given turbulence level. Yet, the penetration of pressure
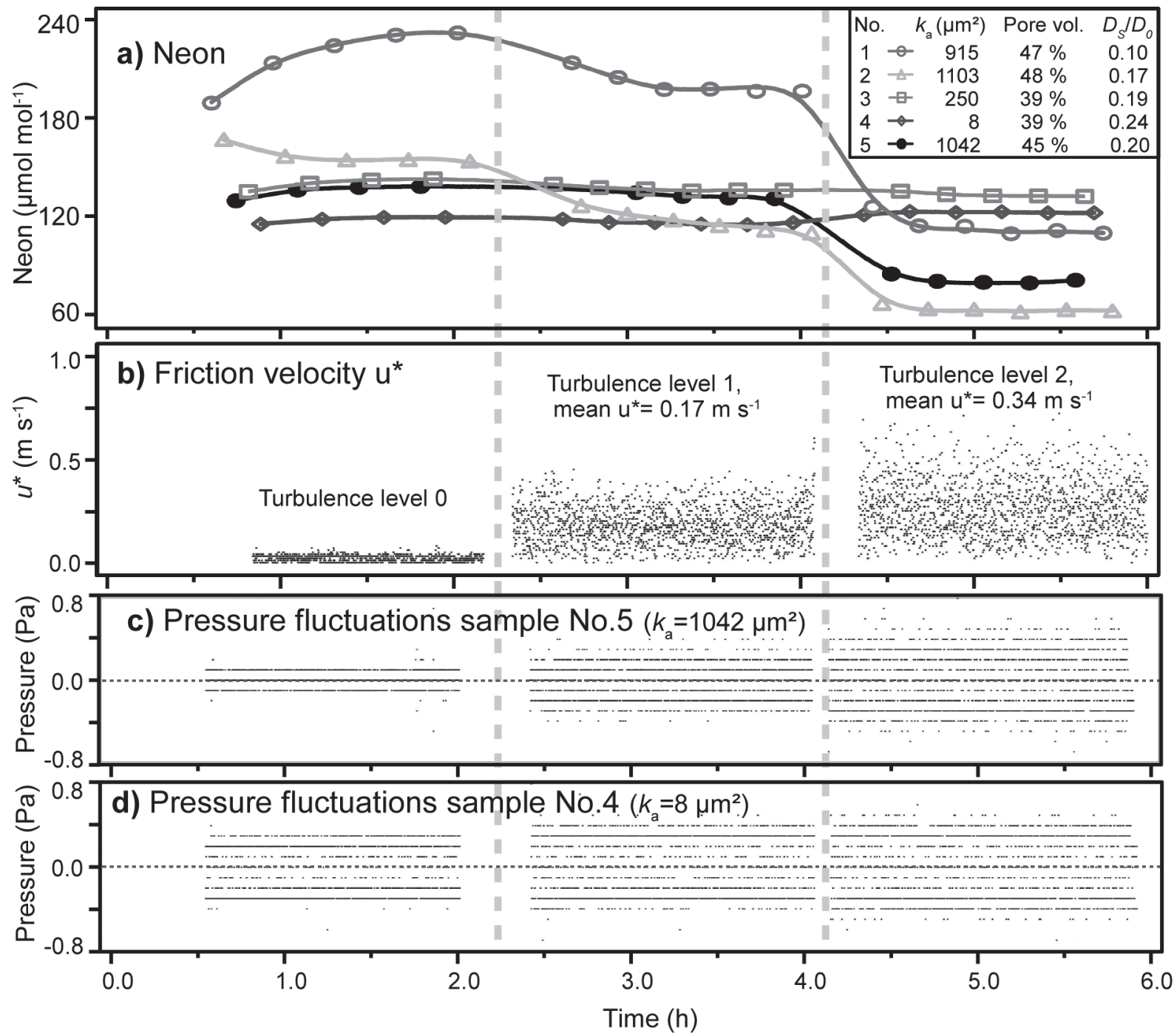

Fig. 5. Test results using plastified soil samples. Time series of (a) the resulting steady-state concentrations of neon in the chamber, (b) friction velocity $u^{*}$, and (c, d) pressure fluctuations within the respective chamber. 


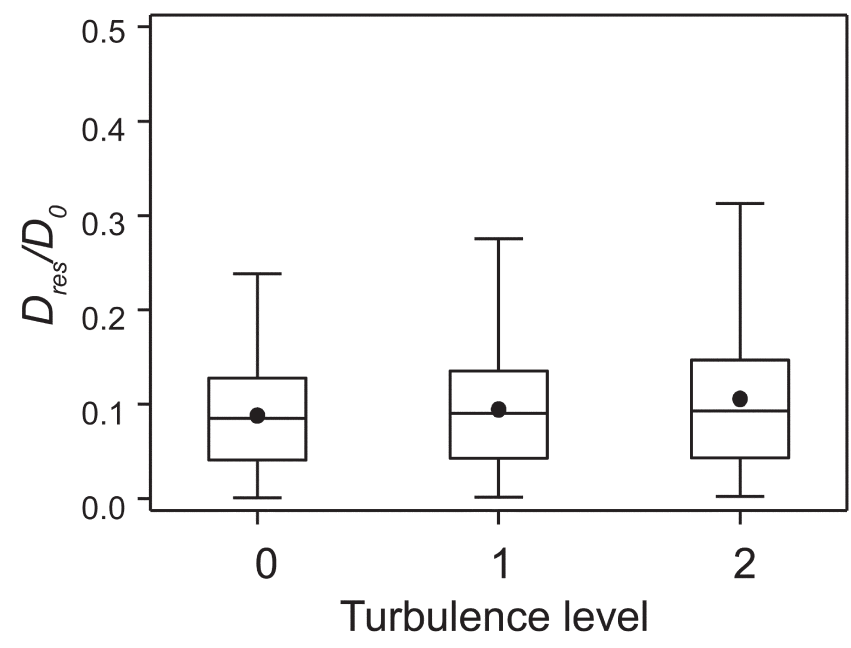

Fig. 6. The relative resulting exchange coefficient $D_{\text {res }} / D_{0}$ at different turbulence levels. The boxes indicate 25 th, 50 th, and 75 th percentiles, the dot the mean value.

fluctuations through the samples depends on the pressure diffusivity, and thus the resulting pressure fluctuation in each chamber was different. The observed pressure fluctuation in the chambers increased with increasing turbulence (Fig. 5c, 5d). This response was stronger for the soil sample with the higher $k_{\mathrm{a}}$ (Fig. $5 \mathrm{c}$ ). The turbulence induced pressure fluctuations in the chambers (excluding the basic fluctuations) increased by $100 \%$ when changing from turbulence Level 1 to Level 2. Thus, an increase by $100 \%$ of the turbulence-induced pressure fluctuations at the sample surface was assumed.

The relative resulting exchange coefficient $D_{\text {res }} / D_{0}$ at a given turbulence level varied widely due to the distinct soil characteristics and the large range in soil moisture of the measured samples (Fig. 6). A statistically significant increase in $D_{\text {res }} / D_{0}$ with increasing turbulence level was obtained using the Friedman test (nonparametric statistical test for paired measurements, $p=0.05)$.
To focus on the effect of pressure pumping only $D_{\text {disp }} / D_{0}$ was considered. To analyze the effect of soil physical parameters on $D_{\text {disp }} / D_{0}$ at a given turbulence level, we tested different parameters. The ratio of air permeability and air-filled pore space $\left(k_{\mathrm{a}} / \varepsilon\right)$ was the best explanatory variable (Fig. 7$) . D_{\text {disp }} /$ $D_{0}$ increased with $k_{\mathrm{a}} / \varepsilon$. Indeed, as this parameter combination describes the soil physical component of the pressure diffusivity, it is able to explain a part of the $D_{\text {disp }} / D_{0}$ variation between the samples $\left(R^{2}=0.48\right.$ at turbulence Level $1, R^{2}=0.38$ at turbulence Level 2). The experimental relationship was compared to modeled ones obtained from Eq. [9] of Massman (2006) who modeled the air-flow velocity in the soil pores to derive $D_{\text {disp }}$ (Fig. 7). To run the model for a situation similar to turbulence Level 1 (Level 2), a pressure fluctuation of $0.5 \mathrm{~Pa}(1 \mathrm{~Pa}$, respectively), and a wave frequency of 1 $\mathrm{Hz}$ were used (values in agreement with the observed increase of pressure fluctuations in the chambers, Fig. 5c, 5d). For the dispersivity $\alpha$ different realistic values were used (Hamamoto et al., 2009).

To compare the importance of the pressure-pumping induced dispersive transport to normal diffusion $D_{\text {disp }}$ was divided by $D_{S}$. The dispersive transport $D_{\text {disp }}$ reached up to $15 \%$ at turbulence Level 1, where no clear relationship between $D_{\text {disp }}$ / $D_{S}$ and other soil physical parameter could be found (including $k_{\mathrm{a}} / \varepsilon$, Fig. 8a). At turbulence Level 2, $D_{\text {disp }} / D_{S}$ reached up to $85 \%$ (probably an outlier, Fig. 8b). Samples with a $k_{\mathrm{a}} / \varepsilon>1000 \mu \mathrm{m}^{2}$ showed substantially higher $D_{\text {disp }} / D_{S}$ values. Single samples showed no turbulence effect, or even a small reduction in $D_{\text {res' }}$, that caused negative values of $D_{\text {disp }}$ to be estimated (Fig. 7). These values become more negative when they are divided by a (low) $D_{S}$ value (Fig. 8). We attribute these negative $D_{\text {disp }} / D_{S}$ values, and also the extreme high outlier, to measurement uncertainty.

\section{Relevance for Sites}

The results of the turbulence experiment proved that $k_{\mathrm{a}} / \varepsilon$ has an important effect on $D_{\text {disp }}$. Thus, we used it as surrogate to determine the sensitivity of the soil gas transport to pressure pumping on a larger data set from our three experimental sites.
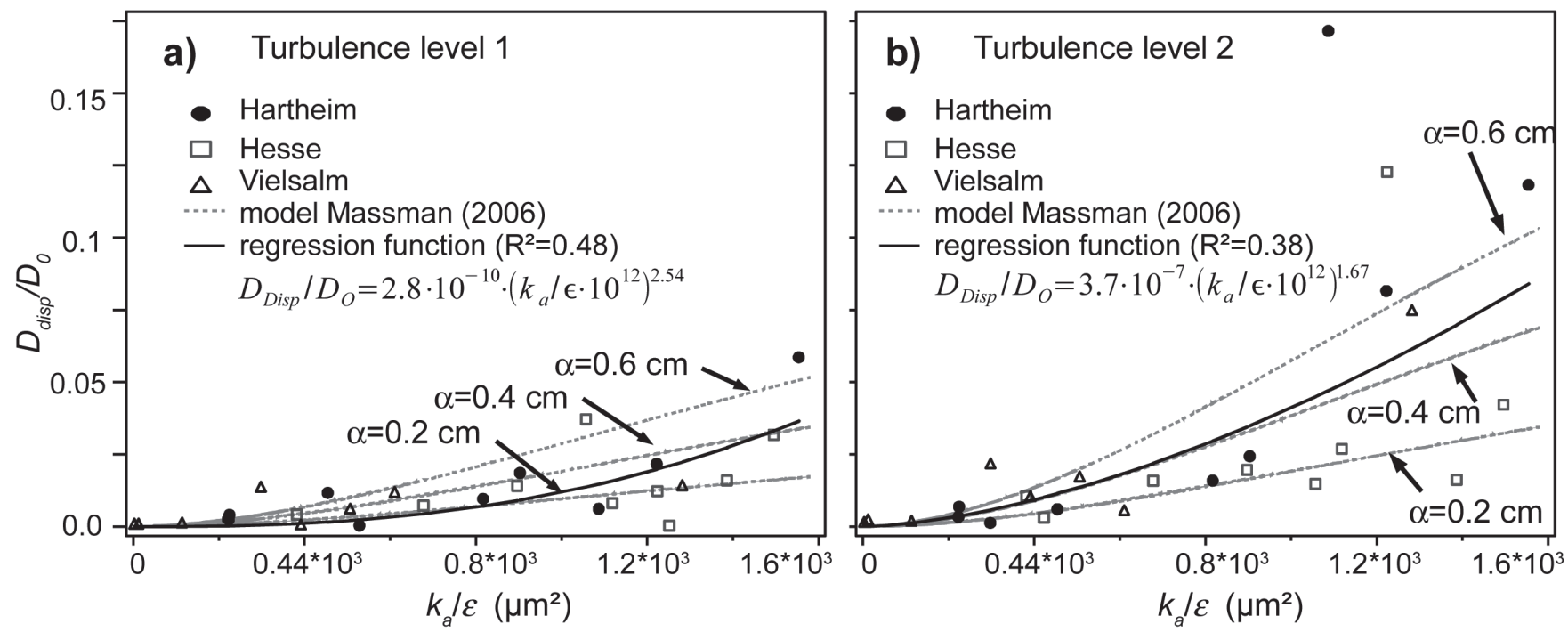

Fig. 7. Relationship between the pressure-pumping effect (measured as the dimensionless relative dispersion coefficient $D_{\text {disp }} / D_{0}$ ) and the parameter combination $k_{\mathrm{a}} / \varepsilon$ for (a) turbulence Level 1 and (b) turbulence Level 2. 

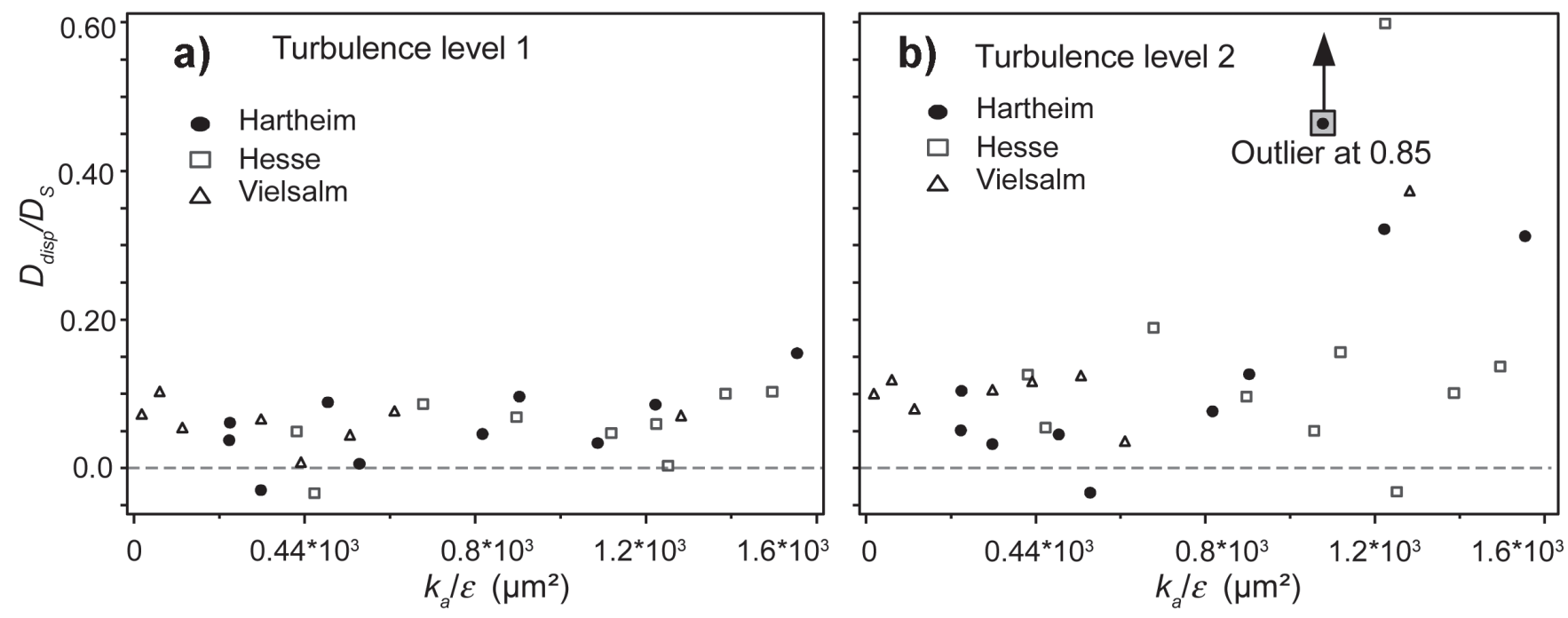

Fig. 8. Relationship between the ratio of gas transport processes (ratio of dispersion coefficient and effective diffusion coefficient, $D_{\text {disp }} / D_{S}$ ) and the parameter combination $k_{\mathrm{a}} / \varepsilon$ for (a) turbulence Level 1 and (b) turbulence Level 2 . Negative $D_{\text {disp }} / D_{S}$ values are due to measurement errors.

Both $k_{\mathrm{a}}$ and $\varepsilon$ depend on the soil-water content and, hence, on soil matric potential. At Hartheim, the topsoil samples (0-5-cm depth) had high $k_{\mathrm{a}} / \varepsilon$ values and soil matric potential had only little impact (Fig. 9). The samples from Hesse revealed lower $k_{d} / \varepsilon$ values at higher soil moisture, but the $k_{d} / \varepsilon$ values were high. The Vielsalm samples generally had the lowest $k_{\mathrm{a}} / \varepsilon$ values that slightly increased when the soil was drier.

\section{DISCUSSION}

\section{Laboratory Experiment}

We could demonstrate the effect of turbulence-driven pressure pumping on gas transport in soil core samples through the activation of mechanical dispersion processes. Using the present set-up, it was possible to relate turbulence directly to the pressure-pumping effect and $D_{\text {disp }}$. The dispersion term, $D_{\text {disp }}$, is the product of the dispersivity, $\alpha$, and the gas velocity in the soil pores $\left(D_{\text {disp }}=\alpha|v|\right)$, which are parameters that are difficult to measure individually.

Until now, most of the experimental set-ups that have been used to measure $\alpha$ in the gas phase are based on the detection of the breakthrough curve of tracer gas when air is flowing continuously through porous media (e.g., Poulsen et al., 2008; Hamamoto et al., 2009). However, these set-ups cannot be used to examine the pressure-pumping effect on the gas transport. We also wonder whether this $\alpha$ value corresponds to the $\alpha$ value for oscillating flow. Our set-up could also be adapted to field experiments to assess the impact of pressure pumping in the field, avoiding the determination of the individual parameters $\alpha$ and $v$.

Over the three sites investigated, the parameter combination $k_{\mathrm{a}} / \varepsilon$ seems to be a suitable and physically-based surrogate to assess the sensitivity of gas transport in a soil to turbulence-driven pressure pumping. The relationship between $k_{\mathrm{a}} / \varepsilon$ and $D_{\text {disp }}$ (Fig. $7)$ in soil samples with large ranges of pore sizes and structure shows that $k_{\mathrm{a}} / \varepsilon$ is the dominant soil property affecting the effectiveness of the pressure-pumping effect at the sample surface and agrees with predictions from the Massman (2006) model. In addition, our results show the need for accurate site-specific parameter determination. Simple models, which calculate $k_{\mathrm{a}}$ based on $\varepsilon$, already fix the relation between $k_{a}$ and $\varepsilon$. However, this ratio can vary greatly between sites (Fig. 4). Therefore, we emphasize measurement instead of modeling the relevant soil physical parameters $k_{\mathrm{a}}$, $\varepsilon$, and even $D_{S}$.
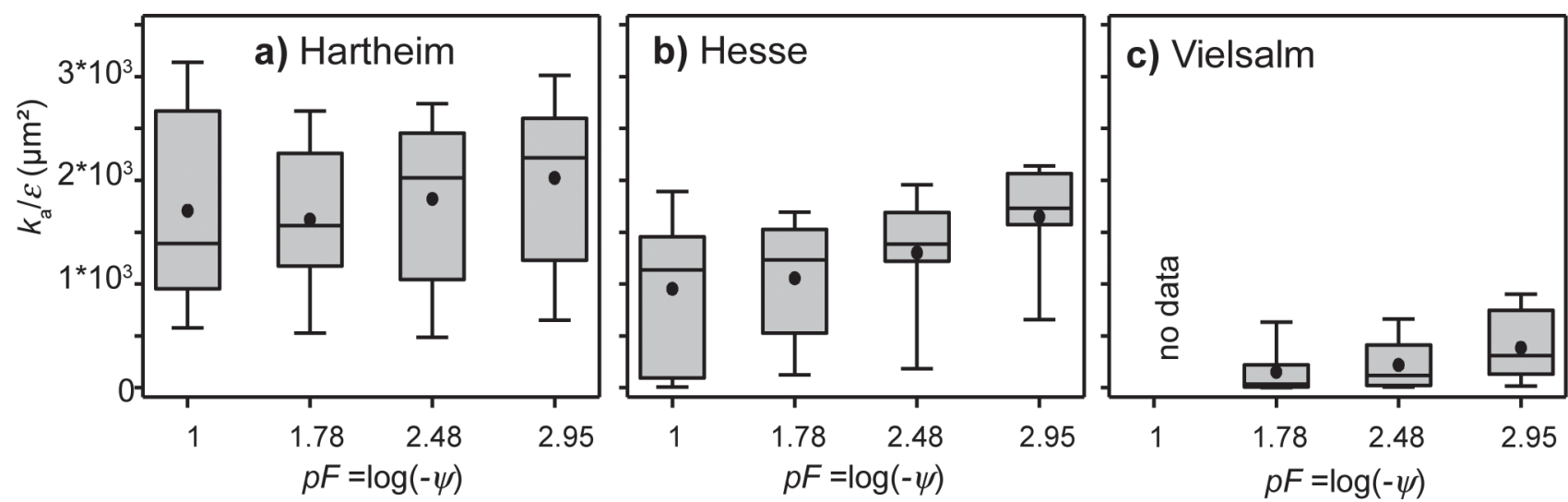

Fig. 9. Relationship between $k_{\mathrm{a}} / \varepsilon$ and $p F$ of topsoil samples $\left(0-5-\mathrm{cm}\right.$ depth), where $k_{\mathrm{a}} / \varepsilon$ is a surrogate for the susceptibility of a soil to pressure pumping, and $p F$ the soil moisture status $[p F=\log (-$ matric potential)]. 
The turbulence-induced dispersive enhancement of the gas transport reached up to approximately $60 \%$ of the transport due to regular diffusion $\left(D_{\text {disp }} / D_{S}\right)$. However, an enhancement $>20 \%$ could only be observed at the higher turbulence level on samples with a $k_{\mathrm{a}} / \varepsilon>1000 \mu \mathrm{m}^{2}$ (Fig. 8). Even though $1000 \mu \mathrm{m}^{2}$ is very high for mineral soil, it is quite common for the humus layer. This threshold cannot be seen as a fixed value but rather depends on the intensity of the pressure pumping and the height of the sample. Hence, the uppermost few centimeters of the humus layer are always potentially affected by the turbulence effect.

The dispersivity $\alpha$ is an important parameter proportional to $D_{\text {disp }}(=\alpha \times v)$ at a given level of pressure pumping (Poulsen and Møldrup, 2006). It depends mainly on the geometry of the air-filled pores (Hamamoto et al., 2009), which is also influenced by soil moisture. Because $k_{\mathrm{a}} / \varepsilon$ can also depend on soil moisture (Fig. 8, see Hesse and Vielsalm), $k_{\mathrm{a}} / \varepsilon$ and $\alpha$ may covary negatively. Thus, higher soil-water content could lead to a lower $k_{\mathrm{a}} / \varepsilon$ value (Fig. 9) and probably also to higher $\alpha$ values (Costanza-Robinson and Brusseau, 2002). This could partly explain the relatively high $D_{\text {disp }} / D_{0}$ values of a Vielsalm samples at low values of $k_{\mathrm{a}} / \varepsilon$, which exceed the modeled values (Fig. 7). Thus, modeling the pressurepumping effect on soil gas transport could be improved using sitespecific moisture dependence of $k_{\mathrm{a}} / \varepsilon$ and $\alpha$.

The assumed amplitudes of the pressure fluctuations during our experiment were very low $(0.5 \mathrm{~Pa}, 1 \mathrm{~Pa})$. Yet, the observed increase in pressure fluctuations in the chamber below the soil sample agrees well with the assumed amplitudes and the dampening effect of the soil. These values can be considered realistic, although very low compared to values used in the synthetic datasets of Poulsen and Møldrup (2006) or those measured by Massman et al. (1997). In contrast, our measured $k_{a}$ values were very high, so that even little pressure fluctuations had a substantial effect.

\section{Relevance for Sites}

Comparing the topsoil of the different sites, the samples from Hartheim showed the highest $k_{\mathrm{a}}$ values. This agrees with the high pore volume and the high fraction of macro/interaggregate pores (Fig. 3a). Soil moisture content has only little influence on $k_{\mathrm{a}} / \varepsilon$ (Fig. 9a), and, hence, this soil is sensitive to pressure pumping during all seasons. Because the values of $k_{\mathrm{a}} / \varepsilon$ are high throughout the profile, the pressure fluctuations can easily penetrate deeper into the soil. The penetrating depth is a very important factor. It represents the maximum depth to which the effect occurs. Additionally it affects directly the movement of the air column in the topsoil pores, since a deeper penetration depth means also a higher air-flow velocity in the topsoil pores. Another important issue is the transfer of turbulence above the canopy to the soil surface. At Hartheim the Scots pine canopy is sparse, and atmospheric turbulence can easily affect the soil surface. Therefore we have to expect a relatively large turbulencedriven pressure-pumping impact for this type of forest site during all seasons (e.g., Maier et al., 2010).
At the Hesse site $k_{\mathrm{a}} / \varepsilon$ (Fig. 9c), and thus $D_{\text {disp }}$ at a given pressure fluctuation level, is generally lower. This means that the soil is less sensitive to pressure pumping than at Hartheim. Additionally, soil moisture has a more important influence. During summer the soil is drier leading to higher $k_{\mathrm{a}} / \varepsilon$ values and the soil gas transport becomes more sensitive to pressure pumping. However, the canopy of the beech stand is dense and only strong wind situations may induce turbulence near the forest floor. Poulsen and Møldrup (2006) suggested that turbulence-induced $D_{\text {disp }}$ would become more important at higher soil moisture contents, because the relative contribution to the soil aeration $\left(D_{\text {disp }} / D_{S}\right)$ increased. As a result, pressure pumping could be important at Hesse during winter, when the diffusivity is low.

At the Vielsalm site we expect atmospheric turbulence to have only little effect on soil gas transport, because $k_{\mathrm{a}} / \varepsilon$ is usually low (Fig. 9c). Especially during winter when there is no dense canopy the soil moisture is high and $k_{\mathrm{a}} / \varepsilon$ minimal. But also here pressure pumping could be important, since the diffusivity is also low.

To include turbulence-driven pressure pumping in field studies, precise information about the pressure fluctuation at the soil surface is needed. Additionally to the amplitude of the pressure fluctuation also wave frequency and wavelength is needed (Farrell et al., 1966; Kazanskiy and Zolotokrylin, 1994; Massman, 2006), which is difficult to measure. Seok et al. (2009), Massman and Frank (2006), and Bowling and Massman (2011) used wind speed as a surrogate for the pressure pumping, while Flechard et al. (2007), and Maier et al. (2010) used friction velocity $u^{*}$. Improvement could be made by studies linking $\mathrm{u}^{*}$ and high frequency pressure fluctuations at the soil surface, so wind data could be used to derive information about the pressure pumping. At forest sites, wind is usually measured above the canopy. But the transition of the above-canopy turbulence to pressure fluctuations at the soil surface must also be considered (Aubinet et al., 2003). Therefore we recommend to measure $u^{*}$ above the soil surface as well. An approach to overcome the uncertainties from parametrization of $D_{S}$ and $D_{\text {disp }}$ would be to continuously measure the vertical profile of $D_{\text {res }}$ in situ, similar to the radon method applied by Davidson and Trumbore (1995).

\section{CONCLUSIONS}

We showed how turbulence-driven pressure pumping can substantially enhance soil gas transport. We strongly recommend considering the turbulence effect on soil gas transport during field studies. The resulting diffusivity $\left(D_{\text {res }}\right)$ should be used instead of the effective gas diffusion coefficient $\left(D_{S}\right)$ for studies using the gradient method to measure soil gas efflux. Also efflux measurements using closed chambers are probably biased low compared with turbulencedriven pressure pumping in the field. Closing the chambers temporarily to measure the efflux probably excludes or attenuates the natural atmospheric pressure fluctuations. Hence, soil gas transport is modified and the efflux is probably lower when the chamber is closed.

\section{ACKNOWLEDGMENTS}

We would like to thank Flora Hofmann and Benjamin Eisele for their 
assistance in the laboratory. Our thanks also go to Helmut Mayer for providing the sonic anemometer and technical assistance.

\section{REFERENCES}

Amos, R.T., D.W. Blowes, L. Smith, and D.C. Sego. 2009. Measurement of windinduced pressure gradients in a waste rock pile. Vadose Zone J. 8:953-962. doi:10.2136/vzj2009.0002

Aubinet, M., B. Chermanne, M. Vandenhaute, B. Longdoz, M. Yernaux, and E. Laitat. 2001. Long term carbon dioxide exchange above a mixed forest in the Belgian Ardennes. Agric. For. Meteorol. 108:293-315. doi:10.1016/ S0168-1923(01)00244-1

Aubinet, M., B. Heinesch, D. Perrin, and C. Moureaux. 2005. Discriminating net ecosystem exchange between different vegetation plots in a heterogeneousforest. Agric. For. Meteorol. 132:315-328. doi:10.1016/j.agrformet.2005.08.006

Aubinet, M., B. Heinesch, D. Perrin, and M. Yernaux. 2003. Horizontal and vertical $\mathrm{CO} 2$ advection in a sloping forest. Boundary-Layer Meteorol. 108:397-417. doi:10.1023/A:1024168428135

Bowling, D.R., and W.J. Massman. 2011. Persistent wind-induced enhancement of diffusive $\mathrm{CO}_{2}$ transport in a mountain forest snowpack. J. Geophys. Res., [Biogeosci.] 116:G04006.

Clements, W., and M. Wilkening. 1974. Atmospheric pressure effects on ${ }^{222} \mathrm{Rn}$ transport across the earth-air interface. J. Geophys. Res. 79:5025-5029. doi:10.1029/JC079i033p05025

Costanza-Robinson, M.S., and M.L. Brusseau. 2002. Gas phase advection and dispersion in unsaturated porous media. Water Resour. Res. 28:1-10.

Davidson, E.A., K. Savage, S.E. Trumbore, and W. Borken. 2006. Vertical partitioning of $\mathrm{CO}_{2}$ production within a temperate forest soil. Glob. Change Biol. 12:944-956. doi:10.1111/j.1365-2486.2005.01142.x

Davidson, E.A., and S.E. Trumbore. 1995. Gas diffusivity and production of $\mathrm{CO}_{2}$ in deep soils of the eastern Amazon. Tellus 47B:550-565. doi:10.1034/j.1600-0889.47.issue5.3.x

DeJong, E., and H. Schappert. 1972. Calculation of soil respiration and activity from $\mathrm{CO}_{2}$ profiles in the soil. Soil Sci. 113:328-333. doi:10.1097/00010694-197205000-00006

Delgado, J.M.P.Q. 2006. A critical review of dispersion in packed beds. Heat Mass Transfer 42:279-310. doi:10.1007/s00231-005-0019-0

Elberling, B., F. Larsen, S. Christensen, and D. Postma. 1998. Gas transport in a confined unsaturated zone during atmospheric pressure cycles. Water Resour. Res. 34:2855-2862. doi:10.1029/98WR02037

Fang, C., and J.B. Moncrieff. 1999. A model for soil $\mathrm{CO}_{2}$ production and transport 1: Model development. Agric. For. Meteorol. 95:225-236. doi:10.1016/S0168-1923(99)00036-2

FAO. 2006. World reference base for soil resources 2006. World Soil Resources Rep. 103. FAO, Rome.

Farrell, D.A., E.L. Greacen, and C.G. Gurr. 1966. Vapor transport in soil due to air turbulence. Soil Sci. 102:305-313. doi:10.1097/00010694-196611000-00005

Flechard, C., A. Neftel, M. Jocher, C. Ammann, J. Leifeld, and J. Fuhrer. 2007. Temporal changes in soil pore space $\mathrm{CO}_{2}$ concentration and storage under permanent grassland. Agric. For. Meteorol. 142:66-84. doi:10.1016/j. agrformet.2006.11.006

Fukuda, H. 1955. Air and vapor movement in soil due to wind gustiness. Soil Sci. 79:249-256. doi:10.1097/00010694-195504000-00002

Gidda, T., D. Cann, W.H. Stiver, and R.G. Zytner. 2006. Airflow dispersion in unsaturated soil. J. Contam. Hydrol. 82:118-132. doi:10.1016/j. jconhyd.2005.09.005

Granier, A., P. Biron, and D. Lemoine. 2000. Water balance, transpiration and canopy conductance in two beech stands. Agric. For. Meteorol. 100:291308. doi:10.1016/S0168-1923(99)00151-3

Granier, A., N. Breda, B. Longdoz, P. Gross, and J. Ngao. 2008. Ten years of fluxes and stand growth in a young beech forest at Hesse, North-eastern France. Ann. For. Sci. 65:704. doi:10.1051/forest:2008052

Hamamoto, S., P. Moldrup, K. Kawamoto, T. Komatsu, and D.E. Rolston. 2009. Unified measurement system for the gas dispersion coefficient, air permeability, and gas diffusion coefficient in variably saturated soil. Soil Sci. Soc. Am. J. 73:1921-1930. doi:10.2136/sssaj2009.0012

Hartge, K.H., and R. Horn. 1999. Die physikalische Untersuchung von Böden. 3rd ed. Ferdinand Enke Verlag, Stuttgart. (In German.)

Hirsch, A.I., S.E. Trumbore, and M.L. Goulden. 2004. The surface $\mathrm{CO}_{2}$ gradient and pore-space storage flux in a high-porosity litter layer. Tellus 56B:312321. doi: $10.1111 / j .1600-0889.2004 .00113 . x$
Holst, J., R. Barnard, E. Brandes, N. Buchmann, A. Gessler, and L. Jaeger. 2008. Impacts of summer water limitation on the carbon balance of a Scots pine forest in the southern upper Rhine plain. Agric. For. Meteorol. 148:18151826. doi:10.1016/j.agrformet.2008.06.008

Iversen, B.V., P. Schjønning, T.G. Poulsen, and P. Moldrup. 2001. In situ, on-site and laboratory measurements of soil air permeability: Boundary conditions and measurement scale. Soil Sci. 166:97-106. doi:10.1097/00010694200102000-00003

Jassal, R., T. Black, G. Drewitt, M. Novak, Z. Nesic, and D. Gaumont-Guay. 2005. Relationship between soil $\mathrm{CO}_{2}$ concentrations and forest-floor $\mathrm{CO}_{2}$ effluxes. Agric. For. Meteorol. 130:176-192. doi:10.1016/j.agrformet.2005.03.005

Jiao, J.J., and H.L. Li. 2004. Breathing of coastal vadose zone induced by sea level fluctuations. Geophys. Res. Lett.31:L11502. doi:10.1029/2004GL019572

Kazanskiy, A.B., and A.N. Zolotokrylin. 1994. On the missing component in the equation for the land surface heat balance as applied to the heat exchange between the desert or semidesert surface and the atmosphere. BoundaryLayer Meteorol. 71:189-195. doi:10.1007/BF00709226

Kühne, A., H. Schack-Kirchner, and E.E. Hildebrand. 2011. Gas diffusivity in soils compared to ideal isotropic porous media. J. Soil Sci. and Plant Nutrition 175(1):34-45. doi: 10.1002/jpln.201000438.

Maier, M., H. Schack-Kirchner, E.E. Hildebrand, and J. Holst. 2010. Pore-space $\mathrm{CO}_{2}$ dynamics in a deep, well-aerated soil. Eur. J. Soil Sci. 61:877-887. doi:10.1111/j.1365-2389.2010.01287.x

Massman, W.J. 2006. Advective transport of $\mathrm{CO}_{2}$ in permeable media induced by atmospheric pressure fluctuations: 1 . An analytical model. J. Geophys. Res. 111:G03004. doi:10.1029/2006JG000163

Massman, W.J., and J.M. Frank. 2006. Advective transport of $\mathrm{CO}_{2}$ in permeable media induced by atmospheric pressure fluctuations: 2 . Observational evidence under snowpacks.J. Geophys. Res. 111:G03005. doi:10.1029/2006JG000164

Massman, W.J., R.A. Sommerfeld, A.R. Mosier, K.F. Zeller, T.J. Hehn, and S.G. Rochelle. 1997. A model investigation of turbulence-driven pressure-pumping effects on the rate of diffusion of $\mathrm{CO}_{2}, \mathrm{~N}_{2} \mathrm{O}$, and $\mathrm{CH}_{4}$ through layered snowpacks. J. Geophys. Res. 102:18851-18863. doi:10.1029/97JD00844

Millington, R.J. 1959. Gas diffusion in porous media. Science (Washington, DC) 130:100-102. doi:10.1126/science.130.3367.100-a

Moldrup, P., T. Olsen, T. Yamaguchi, P. Schjonning, and D.E. Rolston. 1999. Modelling diffusion and reaction in soil. IX. The Buckingham-BurdineCampbell equation for gas diffusivity in undisturbed soil. Soil Sci. 164:542-551. doi:10.1097/00010694-199908000-00002

Poulsen, T., and P. Møldrup. 2006. Evaluating effects of wind-induced pressure fluctuations on soil-atmosphere gas exchange at a landfill using stochastic modelling. Waste Manage. Res. 24:473-481. doi:10.1177/0734242X06066363

Poulsen, T., W. Suwarnarat, M.K. Hostrup, and P.N.V. Kalluri. 2008. Simple and rapid method for measuring gas dispersion in porous media: Methodology and applications. Soil Sci. 173:169-174. doi:10.1097/SS.0b013e31816408c9

Pumpanen, J., H. Ilvesniemi, L. Kulmala, E. Siivola, H. Laakso, P. Kolari, C. Helenelund, M. Laakso, M. Uusimaa, and P. Hari. 2008. Respiration in boreal forest soil as determined from carbon dioxide concentration proðle. Soil Sci. Soc. Am. J. 72:1187-1196. doi:10.2136/sssaj2007.0199

Schack-Kirchner, H., E. Kublin, and E.E. Hildebrand. 2011. A finite-element regression procedure to estimate depth profiles of $\mathrm{CO}_{2} / \mathrm{N}_{2} \mathrm{O}$ production in soils. Vadose Zone J. 10:169-183. doi:10.2136/vzj2009.0193

Scotter,D.R., and P.A.C. Raats. 1968. Dispersion in porous mediums due to oscillating flow. Water Resour. Res. 4:1201-1206. doi:10.1029/WR004i006p01201

Scotter, D.R., and P.A.C. Raats. 1969. Dispersion of water vapor in soil due to air turbulence. Soil Sci. 108:170-176. doi:10.1097/00010694-196909000-00004

Seok, B., D. Helmig, M.W. Williams, D. Liptzin, K. Chowanski, and J. Hueber. 2009. An automated system for continuous measurements of trace gas fluxes through snow: An evaluation of the gas diffusion method at a subalpine forest site, Niwot Ridge, Colorado. Biogeochemistry 95:95-113. doi:10.1007/s10533-009-9302-3

Sharma, P., and T. Poulsen. 2010. Gas dispersion and immobile gas content in granular porous media: Effect of particle size nonuniformity. Soil Sci. 175:426-431. doi:10.1097/SS.0b013e3181f0edaf

Soil Survey Staff. 2006. Keys to Soil Taxonomy. 10th ed. NRCS, Washington, DC.

Stull, R.B. 1988. An introduction to boundary layer meteorology. Kluwer Acad. Publ., Dordrecht, the Netherlands.

Takle, E.S., W.J. Massman, J.R. Brandle, R.A. Schmidt, X. Zhou, I.V. Litvina, R. Garcia, G. Doyle, and C.W. Rice. 2004. Influence of high-frequency ambient pressure pumping on carbon dioxide efflux from soil. Agric. For. Meteorol. 124:193-206. doi:10.1016/j.agrformet.2004.01.014 